\title{
Psychological Effects \& Panic Regarding Corona Virus
}

\author{
Akanksha Kumari ${ }^{1}$, Ranjit Ambad ${ }^{2}$ and Nandkishor Bankar ${ }^{3}$ \\ ${ }^{1}$ First Year Mbbs Student Datta Meghe Medical College, Shalinitai Meghe \\ Hospital and Research Centre, Nagpur, India \\ ${ }^{2}$ Department of Biochemistry Datta Meghe Medical College, Shalinitai Meghe \\ Hospital and Research Centre, Nagpur, India \\ Department of Microbiology Jawaharlal Nehru Medical College, Datta Meghe \\ Institute of Medical Sciences Sawangi (Meghe) Wardha, India \\ Corresponding author email: ambad.sawan@gmail.com
}

\section{ABSTRACT}

After the hike of the Coronavirus from the country of China in the end of previous year, Novel Coronavirus, accounts for total of about 46million cases all around the world with death of more than 1.28 million individuals $\& 31.8$ million recoveries. Beside Its extraordinary infectivity \& casualty rates, Corona Virus Disease has caused widespread panic, economic weight \& budgetary misfortunes . Mass terror of CORONA VIRUS, named as 'corona phobia”, has made an adequate mental indications in over-all population. Along these lines, this audit has been embraced to characterize panic consequence of CORONA Virus. Quarantine can create extreme anger, nervousness, accumulating, psychological illness \&t sadness. Strengthened through an "infodemic" extent through various foundation in web-based broadcasting. Upheavals bigotry, defamation, \& tolerance against specific networks remain additionally being broadly detailed. All things considered, bleeding edge medical services laborers are at higher-danger of getting the illness just as encountering unfriendly mental results in type of burnout, tension, fear of communicating contamination, sentiment of contrariness, wretchedness, \& extended substance-reliance. Network based alleviation projects to battle corona virus will upset youngsters normal way of life \& may cause flowery psychological depression. Networks remain pretentious by disease in several manners \&t want exceptional consideration.

\section{KEY WORDS: CORONA PHOBIA, CORONA VIRUS, MENTAL INDICATION, TERROR. CASUALTY, MISFORTUNES.}

\section{INTRODUCTION}

Social improvement perhaps is experiencing maximum essential junction of thousands years while its presence is being tried through the ascent of a novel genuine exceptional breathing condition wherever on the planet rapidly. The Corona Virus Disease scene has been broadcasted an overall general prosperity emergency on January end, this year through the World Health

Biosc Biotech Res Comm P-ISSN: 0974-6455 E-ISSN: 2321-4007

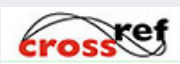

Identifiers and Pagination

Year: 2021 Vol: 14 No (7) Special Issue

Pages: $13-17$

This is an open access article under Creative

Commons License Attribn 4.0 Intl (CC-BY).

DOI: $h t t p: / / d x$.doi.org/10.21786/bbrc/14.7.4
Organization by method of the disorder, at first reported start from China toward the finish of earlier year, continues flooding over the landmasses controlling various countries as of Asia, America \&t Europe seriously spreading contamination. A wide segment of all out populace right now is essentially limited towards their homes, due to cross country lockdowns \& home-limitation frameworks executed in a large portion of the Corona virus smash countries after China to additional ailment spread. Random, quick exchange of disorder has been causing tenseness $\&$ wretchedness, according to World Health Organization are trademark mental responses to the self-assertively evolving condition.

Threatening mental outcomes among normal people are relied upon to augment basically due to the pandemic itself \& moreover as a result of steady movement of immediately open information \&t sustained

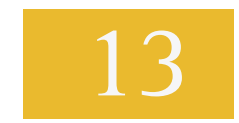


illuminating by methods for online relational association organizations of essentially all structures. As a result, rapidly developing far reaching frenzy \&t outrage because of Corona infection will cause mental issues \& monetary issues, which may be considerably more unfavorable as time goes on than the disease itself . Prior assessments explained that mental flourishing had been seriously affected in such an overall pandemic. Thusly, it is essential to choose the distinctive expected habits by which corona virus pandemic will influence the world's passionate health. In this establishment we evaluate the huge psychosocial results \&t impact of Corona Virus happening .

Stigma Of Corona Virus: Illness related defamation among the victims from 2003 severe acute respiratory syndrome episode was strikingly clear even following quite a while of presentation, making it hard for some, while restarting the standard traditions of everyday life. Additionally, the Corona virus flare-up may likewise offer ascent to demonizing issues such as terror of loneliness, prejudice, separation, besides minimization by all its social plus financial implications. A slandered network will in general look for clinical consideration late Et shroud significant clinical history, especially of movement. This conduct, will build the danger of network transmission. The WHO has likewise given explicit psychosocial contemplations for subsiding the developing disgrace of Corona virus. Wellbeing wrongdoing started out of the terror of being crown positive been accounted for India. (Samantha K 2020 Et J J Liu 2020).

Problem in quarantine $\mathbb{C}$ isolation: Corona virus affected various nations over the world to complete early disconnect exercises as the essential overpowering desire Instrument. Neighboring genuine sufferings, the delayed consequences of this distinctive on the eager thriving $\mathrm{Ct}$ prospering at individual \&t people stages are a couple of overlay. Constrained bundle pull out endeavor by crosscountry locking tries can pass on all over rage, strain \& t torment. considering areas equivalent sentiment of getting cornered \& loss of control. This can be extended if families need parcel, by weakness of debasement headway, insufficient lithely of central things, budgetary disasters, Ct expanded.

impression of risk, which by \& gigantic get redesigned by dull information \& senseless trades through media in the early phase of an affliction. Past scenes have reported mental impact of discrete can move from quick effects, like grouchiness, fear of contracting \&t spreading disease to family members, shock, frustration, weakness, refusal, pressure, distress, a resting issue, despair, to cutoff purposes of results, including breakdown. Suspected separated cases may encounter the savvy impact s of strain due to weakness about their flourishing status \& make constant signs, for instance, temperature checks \&t purifying. Effects, for instance, post-terrible weight issue have been addressed, indications of which associated with the term of separate. Post pullout mental effects may join essential budgetary torment \&t mental signs due to cash related disasters.

Another immense perspective is scolding \&t Social excusal concerning the withdraw cordon in sorts of division, weakness \& avoidance by neighborhood, deficiency with respect to properties, working environment tendency, \& withdrawal from parties. Clinical thought experts are in like manner arranged to see more verifiable pounding than 1 he general individuals for being restricted \&t dependably more impacted intellectually. Youngsters who are (or suspected to be) corrupted with CORONA VIRUSEt need segment or disengage may require astonishing consideration concerning meet their dread, strain \&t other mental properties.

Consistence towards obliged home isolation is routinely being excused In India, not under any condition similar Indifferent nations. This must be taken with most remarkable Idea in any case authority withdrew consent of such cordon will essentially trouble such functions. Certainly all these may accomplish social obstruction, impulsive lead, \& low social Intelligence. Crucial assessment of these Inadequate individuals mind needs further assessments Selfless lead towards selfwithdrawal \&t intentional Isolate should be animated after real explanation through mass correspondence to limit bother $\mathrm{Ct}$ significant length difficulties of obliged separate.

Impact of social media and corona virus: Lately, gigantic Interconnections through online Informal communities (OSN) can conceivably create 'continuous guides' which ought to be viewed as significant devices following an Illness \& for creating interventional crusades once essential. Be that as It may, new data media environments' of the present world, famously named as web-based broadcasting, heartbreaking impacts on control \& results an irresistible illness disease. Inside long stretches of beginning of the CORONA VIRUS flare-up in China, the 'online media alarm' described by tenacious plenty of phony data just as adversely slanted deception metastasized quicker than the Corona virus Itself. WHO mentioned ' Corona virus infodemic" reproducing alarm Et frenzy via spreading out free stunning bits of gossip, colorful news declaration \& emotionalism m? Jumble between accessible certainty sheets \& deficiency of obvious information can be convincing to beg data from the temperamental \&t questionable however promptly accessible online media sources.

When CORONA VIRUS rose to turn into a moving on the web content, numerous bloggers, gatherings or individual clients in social websites began the matter of making a benefit off Corona virus notoriety in numerous rash $\mathrm{Ct}$ erratic blueprints. Since shockingly charged \&t horrifying substance draw the most consideration \&t accumulate the most advancements in online media, a few clients faked Corona virus indications to increase simple fame \&t accordingly deliberately planted mass disarray \&t anger. These welcome various overpowering mental weights in type of nervousness, fear, alarm spells, me lancholy, fixation, touchiness, dreams of having indications like 
Corona virus $\&$ other suspicious thoughts. Medical services searchers are an excess of baffled \&t sullenly stressed over Corona virus manifestations that the ordinary running of medical services frameworks might become upset to speak the mass uneasiness attributable to huge disinformation These conditions of undertakings affirm crude capability of web-based media during a general wellbeing calamity.

Effect on children: Obviously an essential, at any rate unmistakably dismissed issue is the mental effect of Corona disease emit on kids \&t youngsters. Formative brain science examines by $\&$ huge settled tha1 shrewd encounters through ordinary sections during youth initiate the essentials for lifetime direct $\&$ accomplishment as it is a basic stage for mental, vivacious \& psychosocial tendency improvement. During a real pandemic like Corona contamination, network based control programs, for example, shutting of schools, stops, \&t play zones will upset kids' standard way of life \&t can drive bother Et disarray. Both youthful \& more settled kids are in all likelihood going to wind up being moreover referencing, changing up to these changes, \& may show energy, irritation \& antagonism, which in like manner may cause them encountering physical \& mental severity by irrationally pressurized guardians. Stressors, for example, repetition, disappointment. partners \& educators, nonappearance of enough closect dear space at home, \&t family money related misfortunes during lockdowns. all can trigger irritating \& even conceded offensive mental results in adolescents. The connection between their bit by bit plan changes, home confinemen1. \& fear of disease could additionally uplift these disastrous mental responses accomplishing a ceaseless circle. Adolescents upheld by single parent / father, including clinical thought laborers overseeing CORONA VIRUS suffering individual may experience the effects of challenges if their people are kept.

Effect on mature age: The possibility that more prepared adults \& people with authentic comorbidities are particularly exposed against all the more terrible outcomes from CORONA VIRUS can make broad fear among the more established. Other mental Impacts may Join stress, bad temper \&t over the top perception of stress or shock. Those more prepared adults with scholarly rot may end up being essentially extra nervous. upset, Etpublically eliminated, thus definite necessities request express thought. Indoor real exercise might be a potential treatment not only to keep up a healthy real prosperity, yet notwithstanding balance the psychological Impact In this trouble sometime (Liem A et al., 2020).

Overall population: Past assessments have examined an extraordinary \&t wide-ranging extent of psychosocial repercussions that pandemic can execute on everybody. Mass dread of CORONA VIRUS, fittingly named as "crown dread", is likely a consequence of the faulty character other than eccentric course of the disease, predisposition of shortcoming, seen danger of getting the infection, \& so on \& can convey Inverse mental reactions Including maladaptive practices, eager desolation $\&$ dodging response among customary Inhabitants. During illness flare-ups, revives on the central end, quickening In number of new cases \&t expansive media thought can motivate.

Individuals' tensions, disappointments, inadequacy \&t fear over the circumstance. This outcomes In lost success defensive $\&$ help-seeking after practices by excited public that may Incite clashes among clinicians \&t person, which can be harming to torment control adventures \& hamper social steadiness. Over-concerned public may stress over lockdown-related absence of crisis \& fundamental associations, \&t this non-rational out of control situation can incite flabbergasting ends with respect to taking care of reliably essentials or assets (like hand sanitizer, drugs, monitored cover or even tissue). This 'pack lead' can antagonistically impact an association that truly requires those fundamental $\&$ may even advance unconcealed dull showing, Instigating social detachment. Ailment related 'xenophobia” will buy $\&$ enormous move during scourges \& pandemic, as broke down starting at now, \& lamentably has all the stores of being an ordinary reaction If there should be a function of propelling CORONA VIRUS. .There are reports of verbal $\&$ certified assaults against Chinese $\&$ other' Chinese-looking associations, \& keeping them out from portion to clinical thought Etpracticing central fundamental chances.

The extent of restlessness among understudies during the CORONA VIRUS eject In China was unmistakably connected with hampered bit by bit life plans \& deferrals In shrewd exercises as Influenced by the lockdowns. Extended length lockdown causes inaccessibility of association associationset breakdown of different endeavor, Inciting a negative effect on neighborhood \&t public money related strong attributes. Accordingly, a colossal number of Individuals make budgetary afflictions or nearly joblessness, further Increasing the cynical feelings experienced by these people during the CORONA VIRUS pandemic. Crisis clinical associations may correspondingly be affected by lockdowns taking Into account nonattendance of transportation work environments Regardless of whether cross-country lockdown specifically affects close \& dear affiliations, closeness, birth rates, family holding or estimations needs further appraisal \&t assessment.

Implied for individuals seized from the finish of dear associates, assistants, \& friends \& family by virtue of CORONA VIRUS \& the failure to get endet consume can accomplish dissatisfaction, disdain, mental injury\&t extended length mental shriek. Serious watchfulness, vulnerability $\&$ total disharmony are basic issues which may recolor all the phenomenal endeavors taken against the pandemic in India. Reports of expanding brutal direct at home \&t ladles misuse are being spoken to the world over during this pandemic. Vulnerability towards others to the degree disease spread $\&$ the gathering $\&$ clinical thought associations with respect to their capacity $\&$ proficiency to battle the Infirmity may take Its source In this period. (Tsai J., W. M 2020). 
Effect on daily workers \& migrants: By a wide edge by far most of the world's outsiders \&t overall explorer laborers are contained in those countries where general thriving foundation are as of now overstretched $\&$ in zones with the most imperative function of CORONA VIRUS, In this way making these people extravagantly powerless against !Imitation, disfavor \& segment. IMWs everything considered have a high inevitability of average mental issues, similar to trouble \&t a terrible personal satisfaction, which could likewise be risked In view of administrative compelled limit $\&$ lost remuneration during the CORONA VIRUS. Considering the dangerous clarity of this Issue, wanderers, untouchables \& ghetto Inhabitants are at extended danger of contracting \& spreading the contamination.

Inadequacy of adequate, made sure about $\&$ reasonable water deftly makes these social gathering of individuals dismissal to keep essential hat tidiness rules (which has been given most remarkable significance responsible for CORONA VIRUS scene as more than once underscored by government comparatively as thriving Starts) launching to their thoughts of trouble, carelessness \&t separation. Beside, workers \& untouchables may even need to holdup under with the disgrace of staying as a guest wellspring of emit In an association where home-separate has been finished. A cross-country concentrate through China uncovered that transient stars had encountered the most raised level of torture, which was fundamentally more basic than all the occupations. Movements of death while moving, mass compound showering over adventurers, \& t separate on trees or vessels have been spoken to as of India It will test the vital fundamental opportunities for thriving \& sureness which may create mass hatred, opposition $\mathrm{Ct}$ enduring mental disrespect Ghetto tenants may also encounter consistent dread of en-mass launch during this disease inferable from faulty government moves close.

Clearly Corona virus has caused the best lockdown to happen all through the entire presence of headway that can really improve disasters of these explorer laborers, bit by bit bets $\&$ billions of ghetto inhabitants far $\&$ wide. Losing positions leaves these people incompatible to get by $\&$ this surprising incident of pay dejection adds to their flaw, disillusionment. trouble \& mental wretchedness, In the end inciting important shortcoming \& expanded developments of collapse. Imprisonment workplaces are the focal reasons for ground-breaking disease, in this way its success ought to be synchronized in the hour of a plague. Psychosocial necessities, near to all the critical prudent functions, must be tended to with most unprecedented idea. A number of related studies on psychological effects of covid were reported. Other related reviews were reported by Bawiskar et. al., Gaidhane et. al, Burhani et.al and Butola et. al..

\section{CONCLUSION}

Other than CORONA VIRUS, the 21st century is correspondingly the hour of climbing of furor in view of disease uncertainties. Subsequently, mental \& social fervor of this pandemic passes on In general criticalness. The lawmaking body \&t accessories must regard the psychosocial illnesses of this virus \& survey the weight, fatalities \&t related results. Disapproval \& lack focused at networks affected by eject may thwart overall exchange, money $\&$ affiliations, prompting further wretchedness. Due idea should be taken to delete the lack of regard related with Infirmity, inclination, demanding presentation \& psychosocial sway \& should be acknowledged by standard conversations $\mathrm{n}$ with organized \& authority clinical organizations staff by making gathering $\mathrm{ct}$ execution packs who are unmistakably occupied with clinical organizations development structures without making any correspondence openings between system producers \& ground level geniuses.

Enthusiastic prosperity relationship for future pandemics with branches in different countries \& specifically clinical thought establishments for research, mental clinical organizations transport \& orchestrating care program at both individual \& association levels is uncontrollably required. Composed districts \&t comparing helpline numbers might be dispatched for encouraging mental trouble among the overall people concerning this pandemic.

\section{REFERENCES}

Acharya, Sourya, Samarth Shukla, And Neema Acharya (June 2020). "Gospels Of A Pandemic- A Metaphysical Commentary On The Current Covid-19 Crisis.” Journal Of Clinical And Diagnostic Research 14, No. 6: 0a01-2. Https://Doi.Org/10.7860/Jcdr/2020/44627.13774.

Arora, Devamsh, Muskan Sharma, Sourya Acharya, Samarth Shukla, And Neema Acharya. (October 26, 2020) India In 'Flattening The Curve' Of Covid-19 Pandemic - Triumphs And Challenges Thereof." Journal Of Evolution Of Medical And Dental SciencesJemds 9, No. 43: 3252-55. Https://Doi.Org/10.14260/ Jemds/2020/713.

Bawiskar, Nipun, Amol Andhale, Vidyashree Hulkoti, Sourya Acharya, And Samarth Shukla. (November 16, 2020). Haematological Manifestations Of Covid-19 And Emerging Immunohaematological Therapeutic Strategies." Journal of Evolution Of Medical And Dental Sciences-Jemds 9, No. 46: 3489-94. Https://Doi. Org/10.14260/Jemds/2020/763.

Brooks S.K., W. R. S. L. W. L. W. S. G. N., (2020). The Psychological Impact of Quarantine And How To Reduce It Rapid Review Of The Evidence. Lancet

Burhani, Tasneem Sajjad, And Waqar M. Naqvi (July 20, 2020). "Telehealth - A Boon In The Time Of Covid 19 Outbreak." Journal of Evolution Of Medical And Dental Sciences-Jemds 9, No. 29: 2081-84. Https://Doi. Org/10.14260/Jemds/2020/454.

Butola, Lata Kanyal, Ranjit Ambad, Prakash Keshaorao Kute, Roshan Kumar Jha, And Amol Dattaroa Shinde. (September 28, 2020) The Pandemic of 21st Century - Covid-19." Journal Of Evolution Of Medical And Dental Sciences-Jemds 9, No. 39: 2913-18. Https://Doi. 
Org/10.14260/Jemds/2020/637.

Dhankasar, Priya, Pallavi Dhole, Seema Kolhe, Minal Dambare, Priya Rewatkar, And Vaishali Balpande. (2020). The Unseen Positive Effect Of Covid-19 Pandemic." Journal of Research In Medical And Dental Science 8, No. 6: 108-12.

Gaidhane, Abhay M., Zahiruddin Quazi Syed, Lalit Waghmare, Sanjay Zodpey, R. C. Goyal, And S. R. Johrapurkar. (October 2008). Assessing Self-Care Component of Activities And Participation Domain of The International Classification of Functioning, Disability And Health (Icf) Among People Living With Hiv/Aids." Aids Care-Psychological And Socio-Medical Aspects Of Aids/Hiv 20, No. 9: 1098-1104. Https://Doi. Org/10.1080/09540120701808820.

J J Liu, Y Bao, X Huang, J Shi, L Lu (2020). Mental Health Considerations For Children Quarantined Because Of Covid-19. The Lancet Child \& Adolescent Health, 4: 30096-30097.

Liem A., W. C. W. Y. L. C. H. B., (2020). The Neglected Health Of International Migrant Workers In The Covid- 19epidemic. Lancet Psychiatry.

Liu J.J., B. Y. H. X. S. J. L. L., (2020). Mental Health Considerations For Children Quarantined Because of Covi0-19.. Lancet Child Adolesc Health.

0.S, J ., (2020). History In A Crisis• Lessons For Covid19. N Engl J Med Pubmed.

Regmi, Pramod R., Edwin Van Teijlingen, Preeti Mahato, Nirmal Aryal, Navnita Jadhav, Padam Simkhada, Zahiruddin Quazi Syed, And Abhay Gaidhane. (October 2019) The Health Of Nepali Migrants In India: A Qualitative Study Of Lifestyles And Risks.” International Journal Of Environmental Research And Public Health 16, No. 19. Https://Doi.Org/10.3390/Ijerph16193655. Samantha K Brooks, Rebecca K Webster, Louise E Smith, Lisa Woodland, Simon Wessely, Neil Greenberg, Gideon James Rubin (2020). The Psychological Impact Of Quarantine And How To Reduce It: Rapid Review Of The Evidence. The Lancet, 395: 912-920.

Tsai J., W. M.,(2020). Covid•19: A Potential Public Health Problem For Homeless Populations. 